Journal de la Société des Océanistes

\section{Journal de la Société des Océanistes}

$147 \mid 2018$

La Kanaky Nouvelle-Calédonie a rendez-vous avec I'histoire

\title{
Compte rendu de Politique de développement et pauvreté en Nouvelle-Calédonie par Laure Hadj
}

Isabelle Leblic

\section{OpenEdition}

\section{Journals}

Édition électronique

URL : https://journals.openedition.org/jso/9761

DOI : 10.4000/jso.9761

ISSN : 1760-7256

Éditeur

Société des océanistes

Édition imprimée

Date de publication : 15 décembre 2018

Pagination : 607

ISBN : 978-2-85430-136-6

ISSN : 0300-953x

Référence électronique

Isabelle Leblic, "Compte rendu de Politique de développement et pauvreté en Nouvelle-Calédonie par Laure Hadj », Journal de la Société des Océanistes [En ligne], 147 | 2018, mis en ligne le 15 décembre 2018, consulté le 27 septembre 2021. URL : http://journals.openedition.org/jso/9761 ; DOI : https:// doi.org/10.4000/jso.9761

Ce document a été généré automatiquement le 27 septembre 2021.

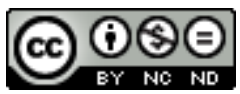

Journal de la société des océanistes est mis à disposition selon les termes de la Licence Creative Commons Attribution - Pas d'Utilisation Commerciale - Pas de Modification 4.0 International. 


\title{
Compte rendu de Politique de développement et pauvreté en Nouvelle- Calédonie par Laure Hadj
}

\author{
Isabelle Leblic
}

\section{RÉFÉRENCE}

HADJ Laure, 2016. Politique de développement et pauvreté en Nouvelle-Calédonie, préface de Serge Paugal, Paris, L'Harmattan, CEPED, coll. Populations, 235 p., graphiques.

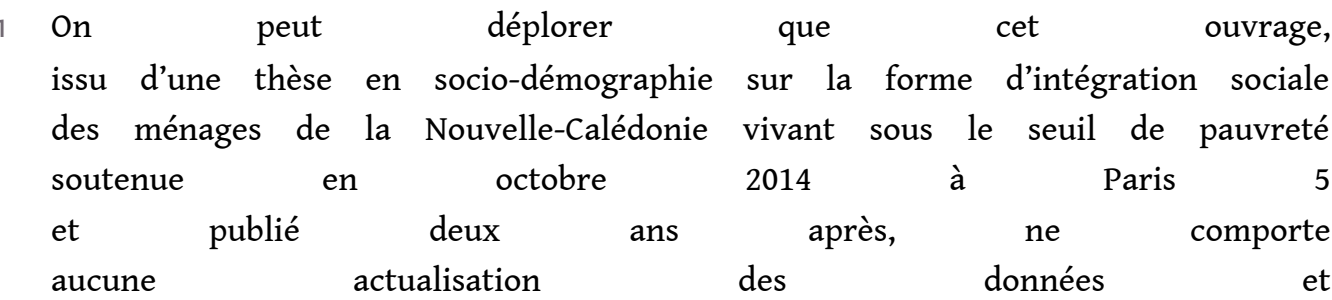
ne soit fondé que sur les données du recensement de 2009 et pas du tout sur celui de 2014.

2 À propos de cette collectivité d'outre-mer française sui generis, Laure Hadj revient sur les indicateurs internationaux, qui présentent la Nouvelle-Calédonie comme un pays développé qui est en réalité marqué par de fortes inégalités de ressources au sein de sa population. Derrière ce constat, se dessinent les modalités de deux systèmes économiques (domestique et marchand) qui cohabitent mais n'attribuent pas le même sens au salariat, aux inégalités de ressources et à la solidarité. En réponse à ces inégalités, l'auteur nous rappelle qu'une politique de développement est instaurée depuis 1989, dont il me semble qu'elle est en fait bien antérieure (Leblic, 1993). L'objet de cette politique de développement est donc, selon l'auteur, de créer les conditions sociales et politiques propices au déploiement d'une économie stable par ce « rééquilibrage » si souvent prôné des inégalités provinciales (îles Loyauté, Nord et Sud) 
et en faveur de la population autochtone notamment, les Kanak. L'auteur traite cette question à partir des recensements de la population et de l'enquête Budget consommation des ménages de l'ISEE et propose une évaluation de cette politique provinciale sur vingt ans. Après avoir dressé un état des lieux de l'évolution des inégalités de diplôme, d'accès à l'emploi et de niveau de vie, elle porte son attention sur les plus vulnérables, c'est-à-dire les ménages vivant sous le seuil de pauvreté relatif. Leur structure de consommation caractérise un système hybride entre les rouages de l'économie marchande et non marchande, traduisant une logique d'intégration sociale qui repose sur un mécanisme de compensation des solidarités privées et publiques. Ce mécanisme est questionné, nous dit-elle, par le renforcement de la solidarité publique depuis les années 2000. À lire donc, mais à compléter par des données plus récentes. 